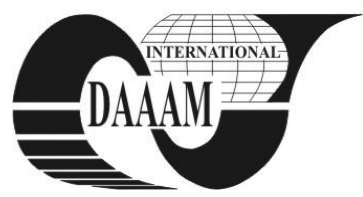

Annals of DAAAM for 2011 \& Proceedings of the 22nd International DAAAM Symposium, Volume 22, No. 1, ISSN 1726-9679 ISBN 978-3-901509-83-4, Editor B. Katalinic, Published by DAAAM International, Vienna, Austria, EU, 2011 Make Harmony between Technology and Nature, and Your Mind will Fly Free as a Bird Annals \& Proceedings of DAAAM International 2011

\title{
TEMPERATURE BEHAVIOUR AT DRILLING BIOCOMPOSITE POLYMERIC
}

\author{
OPRAN, C[onstantin] \& DOBRESCU, T[iberiu] G[abriel]
}

\begin{abstract}
The heat released in the drilling process is generating by the mechanical work, separation and removal of chips from the machining area, and also to overcome the friction between chip, tool and surface rake. The heat resulted during the drilling process, travels from the source to the cold areas, distributing in the drilling tool, chip, perform and environment. Thermal phenomena that accompanying inevitably the drilling process of bio-composites polymeric have a significant influence on the material processed and in a small part on drilling tool during the formation of the chips. For this thermal study, during the drilling process on bio-composite polymeric was used a method named the infrared thermograph. The paper has the aims to determine the temperature influence on the drilling parameters during cutting process.
\end{abstract}

Key words: bio-composites polymeric, temperature behaviour, drilling conditions

\section{INTRODUCTION}

The increasing temperature in the contact area between the tool and the machined surface can cause chemical reactions and structural transformations of the matrix bio-composites polymeric, and can lead to surface degradation caused by cutting, cutting tool wear, etc. Also, having different thermal coefficients of the matrix and reinforced materials can lead to breakage in the interface of the particles and the matrix.( Pickering, 2009). Low resistance to high temperature of the biocomposite polymeric is attributed to low strength reinforced element of the material. The higher values of the temperature have the effect to burning it. This phenomenon is intensified by the low thermal conductivity of polymeric materials. For the reinforced element and polymeric matrix it is recommended that cutting zone temperatures do not exceed $200^{\circ} \mathrm{C}$ (Opran et al., 2009).

The bio-composites polymer cutting products require a strict control of temperature developed in the cutting zone. Cutting parameters adopted must ensure during the cutting process, the contact zone between tool and part, temperatures lower than the temperature of thermal degradation of the material elements of reinforcement. To study the thermal regime of the bio-composite polymer, the method of infrared thermograph was used.

This method is to remote detection of infrared radiation emitted by a product under consideration and processing information by scanning the surface point by point, into a visible image which can reveal the temperature at any point.

\section{EXPERIMENTAL EQUIPMENT}

2.1 Camera used for the study of temperature:

The stand for the study includes a photo-camera for measurement the infrared temperature, model SC640 ThermaCam (1), a computer data processing purchased (2), (Fig. 1.).

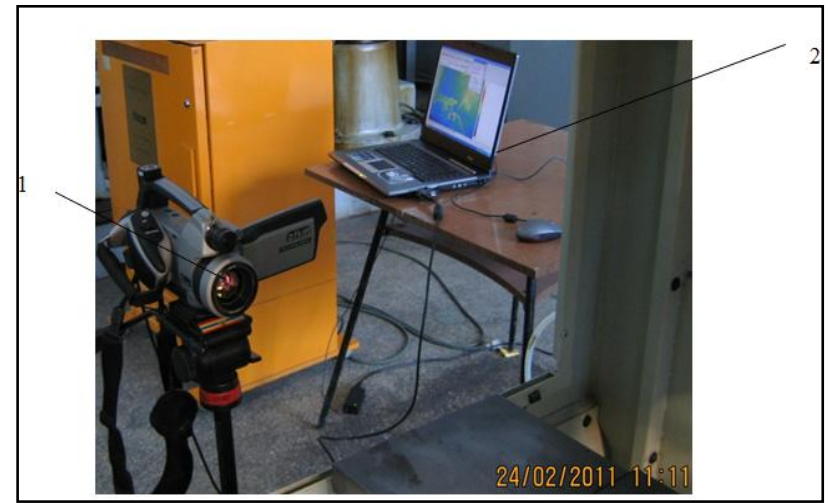

Fig. 1. Stand for the study of temperature

The room of measuring the infrared temperature radiometer detector is a matrix comprised of a network micro bolometer, without separate cooling system, allowing dynamic data recording system.

\subsection{Cutting tool characteristics:}

In order to obtain quality products, the literature calls for drilling materials made by bio-composites polymeric, the use of specialized tools for these types of polymer composite. SANDVIK Coromat companies and Iscar Cutting Tools are the world leader in polymer composite materials in cutting tools for processing depending on the material matrix, the reinforcing nature of the material and arrangement of particles in biocomposite. Drilling tool used is presented in fig. 2.

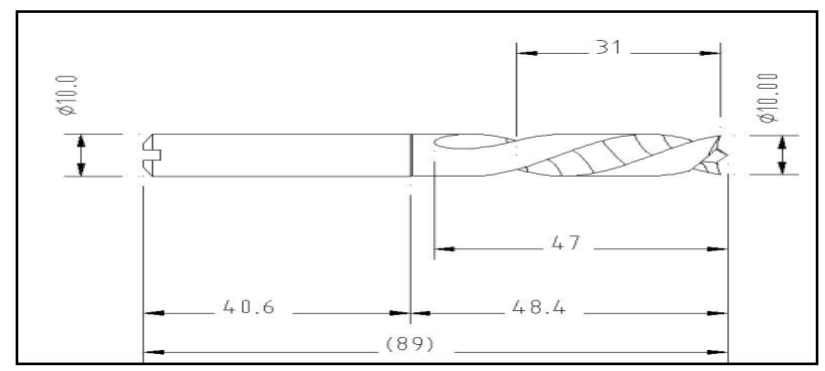

Fig. 2. Drilling tool, used for cutting bio-composite polymeric

\subsection{Characteristics of processed materials}

Material characteristics that affecting machining by drilling are: the nature of the constituent elements, the quality of the interface and the physical, chemical and mechanical properties of bio-composites polymeric. To make samples were chosen as polymer matrix unsaturated polyester resin in organic solvent such HELIOPOL 9431 ATYX LSE and for the reinforced element were chosen wood particles.(Oksman et al., 2008).

In figure 2.3. Are present the samples of the bio-composites polymeric. 


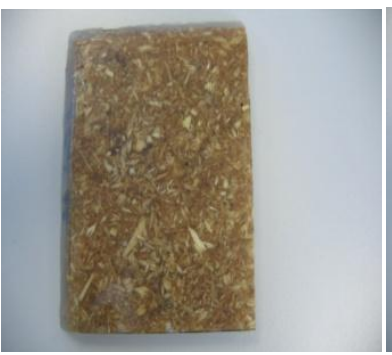

a)

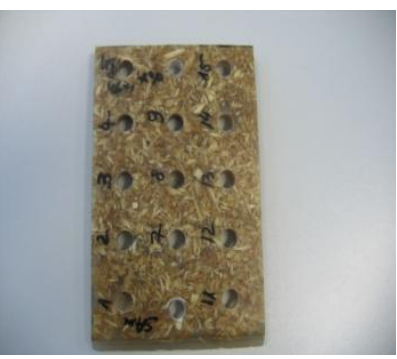

b)
Fig. 3. Sample of the bio-composites polymeric a)sample of the bio-composites polymeric b)processed sample of the bio-composites polymeric

\section{EXPERIMENTAL RESULTS}

Based on experimentally determined, will be drawing a graph that shows the influence between the drilling process parameters over the temperature during drilling process of the sample made by bio-composites polymeric. In the following table 1 . will be presented the drilling regime parameters.

\begin{tabular}{|r|r|r|r|r|}
\hline \multicolumn{1}{|c|}{$\mathrm{f}$} & \multicolumn{1}{c|}{$\mathrm{n}$} & \multicolumn{1}{c|}{$\mathrm{v}_{\mathrm{c}}$} & \multicolumn{1}{c|}{$\mathrm{v}_{\mathrm{f}}$} & Temperature \\
\hline$[\mathrm{mm} / \mathrm{rot}]$ & {$[\mathrm{rot} / \mathrm{min}]$} & {$[\mathrm{m} / \mathrm{min}]$} & {$[\mathrm{mm} / \mathrm{min}]$} & {$\left[{ }^{\circ} \mathrm{C}\right]$} \\
\hline 0.02 & 3000 & 94.2 & 60 & 108.5 \\
\hline 0.05 & 3000 & 94.2 & 150 & 107.1 \\
\hline 0.08 & 3000 & 94.2 & 240 & 103.3 \\
\hline 0.1 & 3000 & 94.2 & 300 & 100.7 \\
\hline 0.12 & 3000 & 94.2 & 360 & 91.4 \\
\hline 0.15 & 3000 & 94.2 & 450 & 86.8 \\
\hline 0.02 & 3500 & 109.9 & 70 & 121.5 \\
\hline 0.05 & 3500 & 109.9 & 175 & 101.2 \\
\hline 0.08 & 3500 & 109.9 & 280 & 96.6 \\
\hline 0.1 & 3500 & 109.9 & 350 & 90.4 \\
\hline 0.12 & 3500 & 109.9 & 420 & 92.8 \\
\hline 0.15 & 3500 & 109.9 & 525 & 85.5 \\
\hline 0.02 & 4500 & 141.3 & 90 & 134.9 \\
\hline 0.05 & 4500 & 141.3 & 225 & 111.1 \\
\hline 0.08 & 4500 & 141.3 & 360 & 103.3 \\
\hline 0.1 & 4500 & 141.3 & 450 & 98.1 \\
\hline 0.12 & 4500 & 141.3 & 540 & 92.1 \\
\hline 0.15 & 4500 & 141.3 & 675 & 87.1 \\
\hline
\end{tabular}

Tab.1. Drilling regime parameters for bio-composite polymeric

In fig. 4. are presented the influences of the cutting feed at the temperature

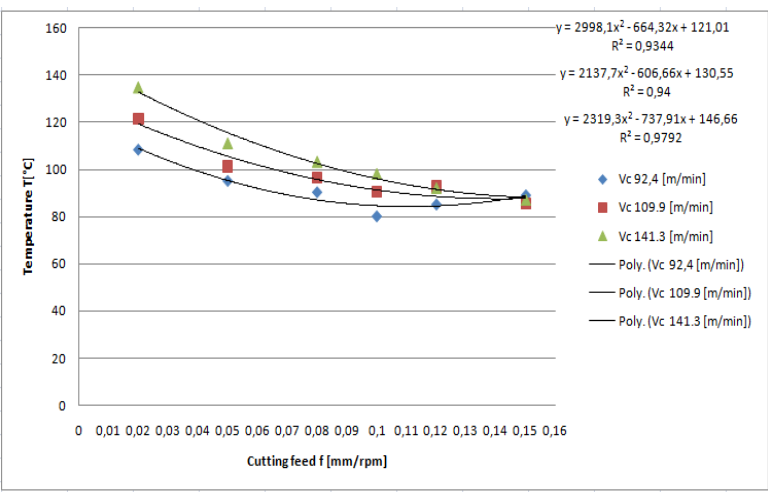

Fig. 4. Influence of the cutting feed at the temperature

Processing of the drilling bio-composites polymer represent the increase of the cutting regime parameters, decreases the temperature developed in the cutting area. Among the parameters of cutting regime bears a great advance on the piece pattern of the thermal field and cutting tools. As the advance is even more developed temperature is lower.

Fig. 5. presented the distribution of the temperature is as both tool and machined surface. We can see in the pictures the greatest amount of heat is in the work piece.

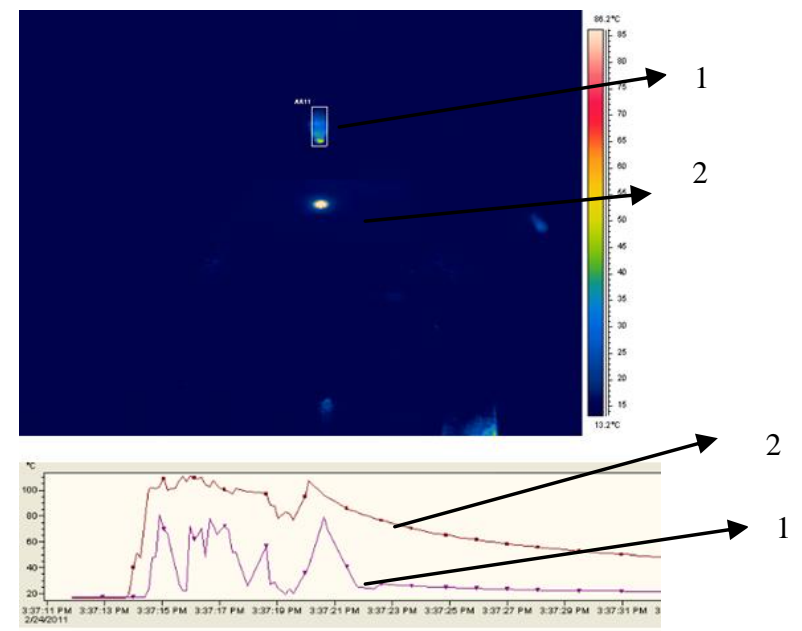

Fig. 5. Temperature distribution in the tool and work piece 1 - Processing tool 2 - Work piece

\section{CONCLUSIONS}

The experimental research carried out showed that due to low thermal conductivity, during the cutting process to produce a rapid temperature rise in the work piece. Analyzing the obtained thermograms distinguish fact that during the cutting process, the heat is taken in most of the piece, then the chips and then the cutting tool. Accompanying phenomena who inevitably are in the process of drilling materials made by bio-composites polymeric, have a significant influence on the material processed and less on drilling tool in chip formation process.

Based on the affirmation above, at the drilling process of materials made by polymeric bio-composites, it requires strict control of temperature developed in the drilling zone. Cutting regime parameters adopted must ensure during the drilling process, in the contact zone between tool and the part, temperatures lower than the temperature of thermal degradation of the material elements of reinforcement.

Folowing plans are to obtain a better quality of machined surface, and this will lead us to increase the resistance of the studied products.

Next steps are to monitor in real-time the process of the temperature in interdependence with the forces and processed surface quality.

\section{REFERENCES}

Oksman, N. K.; Mohini, S. (2008). Wood-polymer composites, WoodHEAD Publishing in Materials, CRC, SUA

Opran, C.; Vasile, N.; Racicovschi, V.; Mohan, G. (2004). Biostructuri polimerice degradabile in mediul natural, Vasile Goldis University Press, Arad, Romania

Opran, C.; Blajină, O. (2009). Temperature field in EDM of ceramics composites, Annals Of Daaam For 2009, Proceedings Of The 20th International DAAAM Symposium, Vol. 20, No. 1, pp. 1519-1522, ISSN 17269679, DAAAM International, Vienna, Austria

Pickering, K. (2009). Properties and performance of naturalfiber composites, University of Waikato, New Zealand

Tsai, S.W. (2008). Strength \& life of composites, Editor Aeronautics \& Astronautics Stanford University, SUA 